\title{
Operation Optimization of Regional Integrated Energy System Based on Electric Heating Gas Demand Response
}

\author{
Nan Wang ${ }^{1, \mathrm{a}}$, Jialin Yang ${ }^{1, \mathrm{a}}$, Xichao Zhou ${ }^{1, \mathrm{a}}$, Zhen $\mathrm{Li}^{1, \mathrm{a}}$, Yaling Sun ${ }^{2, \mathrm{~b}^{*}}$, Yongli Wang ${ }^{2, \mathrm{~b}}$, \\ ${ }^{1}$ State Grid Integrated Energy Service Group Co., Beijing, Ltd. 100053, China \\ ${ }^{2}$ North China Electric Power University, Beijing, 102206, China
}

\begin{abstract}
Taking into account the energy cost, pollution emission, wind power consumption, and other dispatching objectives in the regionally integrated energy system (RIES), the RIES multi-objective optimization model considering the integrated demand response is established. Firstly, the RIES modeling of equipment including electricity-to-gas, energy storage systems, cogeneration units, etc., and the introduction of a comprehensive demand response that specifically considers load reduction, load transfer, and load replacement in the region, aimed at reducing system load peaks and valleys difference. Then, the objective function to minimize the system energy cost, the abandoned wind power, and the pollutant treatment cost was established respectively, and the multi-objective optimization method was adopted - the Pareto front was solved by fuzzy weighted programming traversal weights, and then the decision was made based on evidence Method to find the optimal scheduling strategy. Finally, based on a typical case study, the results show that the proposed multi-objective optimization algorithm can effectively make trade-offs among multiple scheduling objectives, and RIES considering comprehensive demand response has advantages in terms of total energy consumption, environmental friendliness, and wind power consumption.
\end{abstract}

\section{Introduction}

At present, many scholars have done more research on the optimization of integrated energy system operation: A regional grid-connected system based on electric and heating joint dispatch [1]; Considering the dynamic heat transfer characteristics of heating pipes, the time delay and heat loss of the heat transfer system, this document establishes an electric heating IES optimal dispatch model [2]; some researchers Introduce demand-side management into the planning of the electrical interconnection integrated energy system [3]; some scholars have proposed a park microgrid IES response mechanism based on the comprehensive demand of electric and heating loads. The results show that the application of integrated demand response improves the flexibility of park microgrid thermal power production [4]. But the introduction of demand response into RIES to explore the impact of multi-objective is still relatively small.

Therefore, this paper proposes a RIES multi-objective optimization model considering the comprehensive demand-side response. In RIES, economy, environment, wind curtailment, and other aspects are the optimization goals, and comprehensive demand response is introduced to improve the overall performance of the system. The fuzzy weighting method is used to solve the convex optimization Pareto front, and then the evidence-based reasoning decision method is used to give a multiobjective compromise solution. Finally, a typical RIES example is used to verify the effectiveness of the proposed model and method. The energy flow structure diagram of the regionally integrated energy system is shown in Figure 1:

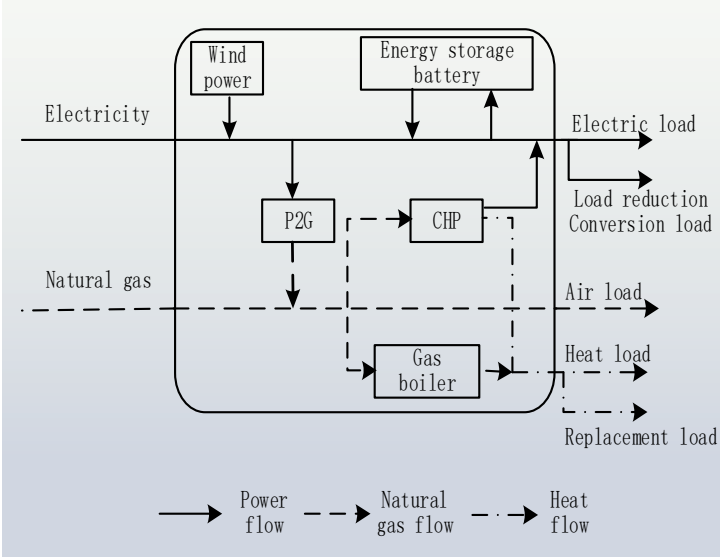

Fig1. The energy flow structure diagram of the regionally integrated energy system

\section{Operational optimization strategy}

\subsection{Objective functions}

\subsubsection{Economic costs}

From an economic point of view, the article considers minimizing the sum of the cost of purchasing energy from 
the external network and the cost of demand response as the economic dispatch decision-making objective, specifically:

$$
\begin{aligned}
& \min F_{C O S T}=C_{\text {buy }}+C_{I D R} \\
& C_{\text {buy }}=\sum_{t=1}^{T}\left(c_{\text {ele }} P_{\text {net }, t}+c_{\text {gas }} Q_{\text {net }, t}\right)
\end{aligned}
$$

\subsubsection{Pollutant treatment cost}

From an environmental point of view, this paper takes the cost of pollutants $\left(\mathrm{NO}_{2}, \mathrm{SO}_{2}\right.$, and PM2.5, etc.) Treatment as the objective function mathematical model for measuring pollutant emissions, specifically:

$$
\min F_{E N}=\sum_{t=1}^{T}\left(\lambda_{n e t} P_{n e t, t}+\lambda_{C H P} P_{C H P, t}+\lambda_{G B} P_{G B, t}\right)
$$

\subsubsection{Abandoned wind power}

To maximize the utilization of renewable energy, the total dispatched wind power is often taken as the objective function. The specific model is:

$$
\min F_{W I N D}=\sum_{t=1}^{T}\left(P_{W, t}^{\text {pre }}-P_{W, t}\right)
$$

\subsection{Constraints}

\subsubsection{Energy balance constraints}

For RIES coupled with electricity, gas, and heat, there are three kinds of energy conservation relationships, specifically:

$$
\begin{aligned}
& \min F_{W I N D}=\sum_{t=1}^{T}\left(P_{W, t}^{\text {pre }}-P_{W, t}\right) \\
& Q_{n e t, t}+Q_{P 2 G, t}=Q_{C H P, t}+Q_{G B, t}+Q_{L, t} \\
& P_{C H P, t}^{h}+P_{G B, t}=P_{L, t}^{\prime h}
\end{aligned}
$$

\subsubsection{External network interaction constraints}

Taking into account the impact of RIES purchase energy On the external distribution network, the purchasing power and natural gas flow are limited to a certain range:

$$
\begin{aligned}
& 0 \leq P_{n e t, t} \leq P_{n e t, \max } \\
& 0 \leq Q_{n e t, t} \leq Q_{n e t, \max }
\end{aligned}
$$

\subsubsection{Electric to gas}

P2G first produces hydrogen through alkaline electrolysis of water and then converts it into hydrogen. Based on this, let hydrogen and $\mathrm{CO} 2$ react under the catalyst to generate methane and water. This methanation process has undergone a two-stage chemical reaction, with a comprehensive efficiency of $45 \%$ to $60 \%$, specifically:

$$
\begin{aligned}
& \eta_{P 2 G} P_{P 2 G, t}=Q_{P 2 G, t} \bullet H_{G V} \\
& 0 \leq P_{P 2 G, t} \leq P_{P 2 G, \text { max }}
\end{aligned}
$$

\subsubsection{Cogeneration unit}

While CHP generates electricity through gas, the waste heat boiler collects waste heat to supply thermal energy, which improves the energy efficiency of the system. The common thermoelectric coupling CHP model is used in this article:

$$
\begin{aligned}
& \eta_{P 2 G} P_{P 2 G, t}=Q_{P 2 G, t} \cdot H_{G V} \\
& P_{C H P, t}^{h}=\eta_{C H P}^{h} Q_{C H P, t} \cdot H_{G V} \\
& 0 \leq P_{C H P, t}^{e} \leq P_{C H P, \max }^{e}
\end{aligned}
$$

\subsubsection{Wind turbine}

In this paper, it is considered that the output of wind turbines will not be higher than the forecasted value of wind power, and the system does not have enough margin to absorb a large amount of wind power during windy periods, and wind abandonment may occur.

$$
0 \leq P_{W, t} \leq P_{W, t}^{p r e}
$$

\subsection{Comprehensive demand-side responses}

From the demand side to further adapt to the dispatching demand, the comprehensive demand response changes the user's electricity consumption behavior through economic incentives. Three demand response methods are considered in the article: 1) Load reduction, reducing the dispatch pressure by reducing the peak load. 2) Load transfer, transfer part of the peak load to the valley load period. This method does not change the total electrical load in the dispatch period. 3) Replacement of load. Part of the load is replaced by other energy supply methods. In this paper, only the thermal load is replaced by the electric load. The specific model is as follows:

$$
\begin{aligned}
& P_{L, t}^{\prime}=P_{L, t}+P_{\text {Cut }, t}+P_{\text {tran }, t}+P_{r e p, t} \\
& P_{L, t}^{\prime h}=P_{L, t}^{h}-P_{r e p, t}
\end{aligned}
$$




$$
\begin{aligned}
& -P_{\text {Cut }, \text { max }} \leq P_{C u t, t} \leq 0 \\
& \sum_{t=1}^{T} P_{\text {tran }, t}=0,\left|P_{\text {tran }, t}\right| \leq P_{\text {tran,max }}
\end{aligned}
$$

\subsection{Algorithm}

The mathematical model established in this paper belongs to the mixed-integer nonlinear programming problem, and the standard form of its solution can be written as:

$$
\begin{aligned}
& \min f(x, y) \\
& \text { s.t. }\left\{\begin{array}{l}
h_{i}(x, y)=0 \\
g_{j}(x, y) \leq 0 \\
x_{\text {min }} \leq x \leq x_{\max } \\
y \leq y_{\text {max }}
\end{array}\right.
\end{aligned}
$$

The model in this paper uses the method of literature to transform it into a mixed-integer linear programming problem. In the Matlab environment, it uses Yalmip to model and calls the Cplex solver to quickly solve it.

\section{Case}

\subsection{Calculation example parameters}

This paper takes the RIES of an industrial park in the north as an example to analyze the effectiveness of multiobjective optimization scheduling and the significance of comprehensive demand response to RIES. The real-time electricity price adopts the method of peak-valley electricity price: peak hour 11: 00-15: 00, 19: 00-21: 00, peak-hour electricity price is 0.900 yuan / $(\mathrm{kW} \cdot \mathrm{h})$; normal time 07: 00-10:00, 16:00-18:00, 22:00-23:00, the usual electricity price is 0.550 yuan $/(\mathrm{kW} \cdot \mathrm{h})$; valley time 01: $00-06: 00,24: 00$, valley hour the electricity price is 0.140 yuan $/(\mathrm{k} \mathrm{W} \cdot \mathrm{h})$. The price of natural gas is 1.050 yuan $/ \mathrm{m} 3$.

\subsection{Analysis of simulation results}

To verify the accuracy of the algorithm, this paper selects a typical northern park for simulation. The simulation results of the balance of supply and demand for different loads and the state changes of energy storage equipment are as follows:

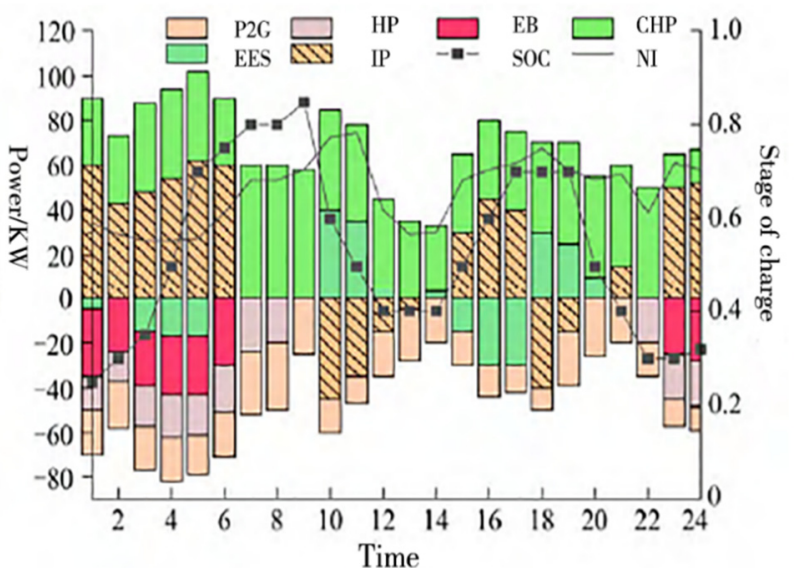

Fig2. OC change curve of electric load balance and electric energy storage

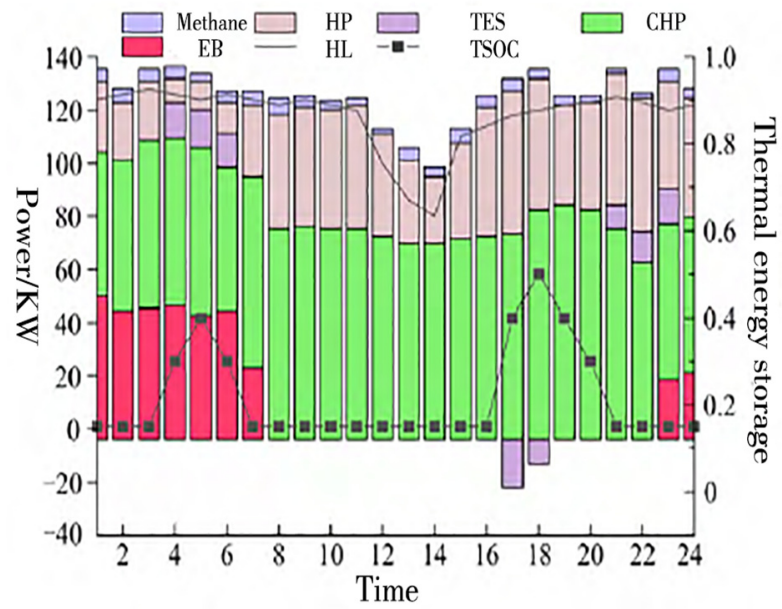

Fig3. Heat load balance and SOC change curve of thermal energy storage

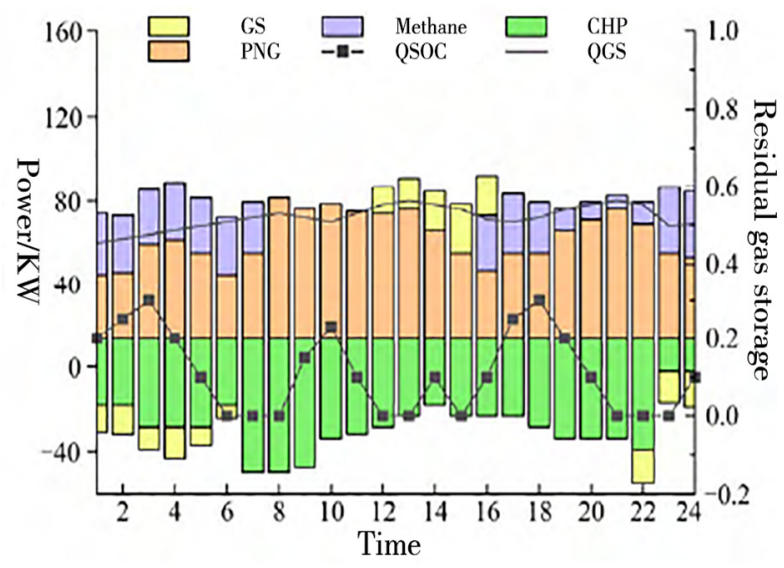

Fig4. Gas load balance and gas storage SOC change curve

In the electric heating gas load operation of the system, when the electricity price is in the low period, the system will guide the electric energy through the electric boiler to convert the electric energy into heat energy and give priority to output, as shown in the period 23:00-07:00 the next day; Electric energy will also be guided through $\mathrm{P} 2 \mathrm{G}$ devices to increase the conversion of electric energy into natural gas, as shown in Figure 3 during the period 23:00 to $07: 00$ the next day, and the $\mathrm{P} 2 \mathrm{G}$ output will be relatively increased. When the electricity price is high and at the 
peak and valley, the system will decouple the cogeneration through thermal energy storage, and the gas-fired unit will increase its output to generate electricity.

Electricity replaces the interactive power with the public grid to meet the demand or sale of electric energy, as shown in Fig.3 time 18:00-20:00; it will also guide P2G to suspend output, as shown in Fig. 4 time period 10:00$14: 00$. When the electricity price is in a normal period, the thermal energy storage releases heat to reduce the output of the gas-fired unit, as shown in Figure 5 during 21:0023:00.

\subsection{Analysis of comparative results}

To specifically analyze the impact of comprehensive demand response on the results of multi-objective optimization, Scenario 1: Comprehensive demand-side response is considered; Scenario 2: Comprehensive demand response is not considered. The scheduling results of the two scenarios are compared, and the specific results are shown in Table 1:

Table1. The influence of comprehensive demand response on the results of multi-objective optimization.

\begin{tabular}{|l|l|l|l|l|l|l|}
\hline \multirow{2}{*}{$\begin{array}{l}\text { Mod } \\
\text { el }\end{array}$} & \multicolumn{2}{|l|}{$\begin{array}{l}\text { Multi-objective } \\
\text { solution }\end{array}$} & $\begin{array}{l}\text { econo } \\
\text { my }\end{array}$ & $\begin{array}{l}\text { abando } \\
\text { n wind }\end{array}$ & $\begin{array}{l}\text { surroun } \\
\text { dings }\end{array}$ & \multicolumn{2}{|l|}{$\begin{array}{l}\text { Multi-objective ideal } \\
\text { solution } \\
\text { my }\end{array}$} & $\begin{array}{l}\text { abandon } \\
\text { wind }\end{array}$ & $\begin{array}{l}\text { surrou } \\
\text { ndings }\end{array}$ \\
\hline $\begin{array}{l}\text { Scen } \\
\text { e1 }\end{array}$ & 1.36 & 276.86 & 1764 & 1.20 & 276.86 & 1499 \\
\hline $\begin{array}{l}\text { Scen } \\
\text { e2 }\end{array}$ & 1.41 & 2140.7 & 2213 & 1.26 & 2140.69 & 1955 \\
\hline
\end{tabular}

It can be seen from Table 1 that the comprehensive demand response has brought significant effects on the three aspects of RIES's economy, environment, and wind power consumption. After the introduction of integrated demand-side response in RIES, the overall cost has been reduced by $3.3 \%$, the output of wind power has increased by $5.6 \%$, and the cost of pollution treatment has been reduced by $20.3 \%$. The introduction of demand response brings relatively little benefit to the overall cost because the implementation of a comprehensive demand response requires subsidies to users, which brings a certain burden to the total cost of RIES.

\section{Conclusion}

Under the framework of RIES, a multi-objective optimization model considering the comprehensive demand-side response and the corresponding solution method are proposed, and the operation optimization requirements of RIES in economic, environmental, and wind power consumption are comprehensively considered, and multiple energy sources in RIES are analyzed. The effect of equipment synergy and comprehensive demand response on multi-objective optimization. Finally, it is verified by a numerical example that the proposed method can effectively make trade-offs among the multiple operational optimization objectives of RIES, the solution speed is faster and the results can be guaranteed to be globally optimal. At the same time, the comprehensive demand response has a positive effect on improving the performance of the system. The next step will focus on how to quickly solve the multi-objective optimization of non-convex models.

\section{Acknowledgements}

The authors would like to thank the support of the project "Science and Technology Foundation of State Grid Corporation of China (5278991900MV)".

\section{References}

1. Xu H., Dong S.F., He Z.X., et al. (2019) Electrothermal comprehensive demand response based on multi-energy complementarity. J. Power System Technology., 43(2): 480-487.

2. Gao Y., Wang P., Xue Y., et al. (2018) Collaborative planning of integrated electricity-gas energy systems considering demand side management. J. Automation of Electric Power Systems., 42(13): 3-11.

3. Wang W.L, Yang L., Wang L., et al. (2018) Optimal dispatch of integrated electricity-heat energy system considering heat storage characteristics of heating network. J. Automation of Electric Power Systems., 42(21): 45-52.

4. Li Z.M., Zhang F., Liang J., et al. (2015) Optimization on microgrid with combined heat and power system. J. Proceedings of the CSEE., 35(14): 3569-3576.

5. Guo C.X., Wang H.R., Zhang Y.N., et al. (2019) Review of "Source-grid-load" co-planning orienting to regional energy Internet. J. Power System Technology., 43(9): 3071-3080.

6. Yang W.T., Wen F.H., Zhang X., et al. (2019) Based on the organic Rankine cycle system Energy trading mechanism. J. Electric Power Construction., 40(12): 11-21.

7. Wei Z.B., Huang Y.H., Gao H.J., et al. (2018) Including electricity-to-gas and thermo-electrolytic coupling cogeneration unit Group's regional energy internet joint economic dispatch. J. Power Grid Technology., 42(11): 3512-3520.

8. Dong S., Wang C.F., Liang J., et al. (2018) Comprehensive energy system that takes into account the operating cost of electricity to gas Multi-objective day-ahead optimal scheduling. J. Automation of Electric Power Systems., 42(11): 8-15, 121. 